\title{
Learning how to learn: Nurturing professional growth through cognitive mapping
}

Mockler, Robert J;Dologite, Dorothy G

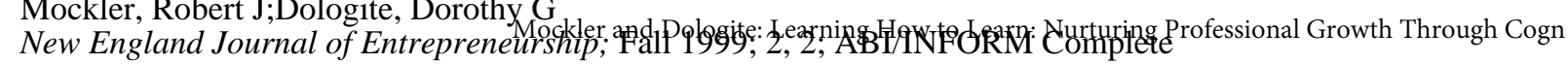
pg. 65

\section{Learning How to Learn: Nurturing Professional Growth through Cognitive Mapping}

\author{
Robert J. Mockler \\ Dorothy G. Dologite
}

This article examines the professional development of entrepreneurs. It describes how cognitive mapping tools drawn from knowledge engineering can be employed to help entrepreneurs both to make decisions and to grow professionally. The first experience described illustrates the decision-making process of becoming an entrepreneur, whereas the second experience describes the decisionmaking process of selecting a franchise offering. The techniques grew out of the experiences involved in adapting basic artificial intelligence modeling tools to teaching more effectively business planning, especially planning entrepreneurial ventures.

$\mathbf{M}$ uch of the work described in this article draws on knowledge engineering technologies. Knowledge engineering is the artificial intelligence discipline that guides the mapping of the thinking (cognitive)/decision processes an expert goes through when making business decisions. ${ }^{1}$ Cognitive skills are needed to do this kind of cognitive mapping. For example, the dependency diagrams (or maps) developed through the approach described in this article, which involves systematically restructuring an expert's thinking processes that were mapped, are then used to develop expert computer systems replicating the expert's thinking processes. Such a process enables an individual to increase his or her professional expertise by learning systematically from modeling experience.

The basic approach of experience-based learning described here is very familiar. For example, when we interact with other people, many of us gradually build mental models (patterns/concepts) of different types of people and how they might be expected to respond to what we say or do. When we meet new people, we use these continually developing mental models to try to anticipate reactions to our words and actions and adjust our words and actions to generate the responses from others we have learned to expect in the past from what we perceive to be similar types of people. We are not always right, and we are constantly refining, retesting, and creating new patterns or models in our mind as we pass through life and its learning experiences. For mystery fans, it is a technique that Miss Marple uses in Agatha Christie's mystery novels to determine who might be a logical murderer suspect.

Business managers and leaders use this same pat- tern-building approach as they gain experience in their professional fields and develop mental models of the heuristics ("if-then" rules of thumb) for handling more and more complex business situations. This mental (cognitive) modeling professional growth process, which can be learned and systematically pursued, is outlined in Exhibit 1.

This article describes an approach to nurturing professional growth through cognitive mapping or modeling techniques. The techniques described are self-learning tools. The objective is to provide readers with such self-learning tools, which they can use on their own, both to make decisions and to increase their expertise in their chosen business professional area. The focus here is on entrepreneurs and entrepreneurial thinking

The article starts with a background discussion section about the origin and definition of cognitive modeling and its contributions to learning. It highlights the relevance of cognitive skills in general and the importance of growing professionally in business in particular. The article continues with two stories about experiences in decisionmaking/action-experiences either of the students themselves or others. These are the specific instances referred to in Exhibit 1.

\section{Cognitive Modeling and Its Contributions to Learning}

Human behavior, according to social learning theory, is in large measure learned through modeling-mainly behavior modeling. ${ }^{2}$ Behavior modeling is an effective way of teaching overt, observable behaviors/activities. ${ }^{3}$ However, behavior modeling falls short when applied to teach covert, cognitive/thinking skills. ${ }^{4}$ Bandura was aware of these limitations and made use of cognitive modeling (or mapping) and its applications to training and learning. ${ }^{5}$ Rooted in behavior modeling, cognitive modeling is a type of observational learning which relies on making hidden mental processes visible to observers. ${ }^{6}$ Cognitive modeling techniques can be used to create qualitative models ${ }^{7}$ useful in business decision-making situations/tasks. ${ }^{8}$ These studies show that with the help of cognitive modeling techniques, situation factors affecting a decision/task can be specified, the heuristics or reasoning steps involved can be traced, and outcomes can be determined.

There are two levels of professional training and development of interest to this study. One is the acquisition of 


\section{Exhibit 1 Reconceptualization for Professional Growth}

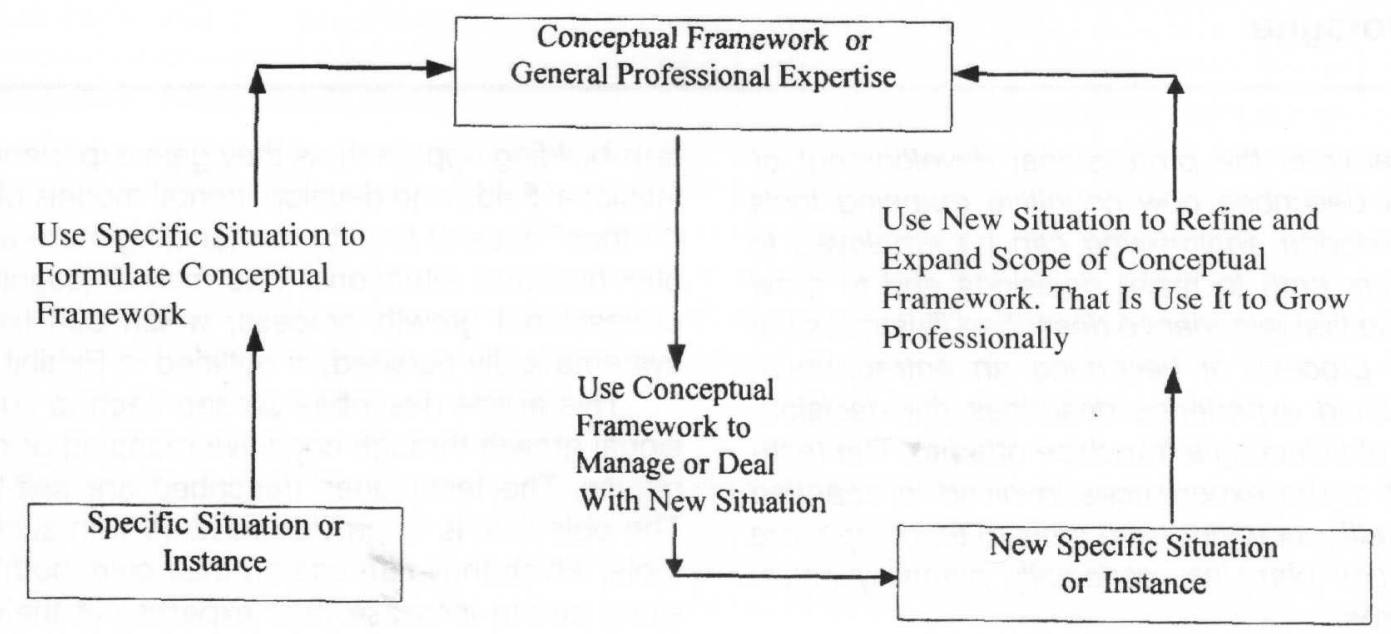

Copyright @ 2000 by R. J. Mockler

knowledge and skills required to perform a certain job or position, such as mechanical engineering or accounting. The second level deals with the acquisition of-that is learning and developing-cognitive (thinking) skills. These conceptual skills are needed to structure and apply related knowledge and previous job experiences to new business/ management situations within an area of professional interest, and therefore help learners (employees or managers) to grow professionally in their jobs.

This article focuses on the second level of professional training and development for business management, a discipline involving often changing and new competitive marketing situations. It extends prior research work by integrating artificial intelligence (expert systems) techniques into the cognitive learning process of graduate (MBA) business students and participants of executive training programs. The cognitive modeling techniques discussed enable the learner to become aware of, articulate, and sharpen his or her own thinking (cognitive) processes. This is known as "metacognition" and is discussed in various studies. ${ }^{9}$ In general, these studies emphasize the importance of metacognition-that is learning how to learn-in personal and professional cognitive training and development. Acquiring the cognitive skills to learn how to learn elevates the student/employee/manager to a stage of the learning process at which the individual is able to control and monitor his or her own cognitive, and therefore, professional development. The cognitive modeling techniques described here are invaluable tools to nurture an individual's professional growth by engaging him or her in a continuous cycle of constant learning on the job.

Cognitive modeling or mapping is used to teach cognitive skills. ${ }^{10}$ These are referred to as "skills" because they are teachable and learnable. While some people have greater natural cognitive (thinking) skills than others, developed either through training and conditioning or through inherited traits," individuals generally have some capacity to learn how to do this kind of learning/modeling better.

There are many effective, easy-to-use techniques/tools available for learning and teaching cognitive skills, techniques, which could be built into any learning program or course. For example, 20 years ago, Edward de Bono provided simple exercises and tools for learning and teaching cognitive skills, such as CoRT, a teaching thinking tool. ${ }^{12}$ CoRT is one of many specific tools de Bono discusses for helping people create generalized models of thinking processes (abstraction and inferential reasoning). The dependency diagrams and their underlying reasoning (i.e., heuristics or rules of thumb) used in this article are another cognitive mapping tool for helping people give useful form to concepts involving how to handle professional management decision situations.

Since then many books and studies have been written about how to teach and learn thinking skills. For example, Richardson, Eyseneck and Piper give a series of papers presented at a Society for Research in Higher 
Education/British Psychological Society (Cognitive Psychology Section) Conference in $1985^{.3}$ The papers discuss the integration of cognitive psychology into higher education by merging the concepts and theories of human cognitive psychology with the evidence and practical implications of research on student learning. Gerard Nierenberg provided similar guidance. ${ }^{14}$

The papers describe different ways to develop cognitive models and use them in teaching.

These include models or maps of reasoning steps involved in making decisions that are useful in helping learn how to reason more effectively. Ways are discussed first of how to model decision heuristics based on observing real-life experiences, and second of how an individual can use these heuristic models both to make decisions and to gain greater expertise in decision-making. In essence, the process moves from a descriptive cognitive mapping (an expert's experiences) to a prescriptive one (how a group of experts might do it more effectively).

Other relevant studies include Boud, Keogh and Walker, Bourne, et al., Phye and Andre, and Trehub. ${ }^{15}$ Additional studies in the related areas of cognition and artificial intelligence discuss the structure of human cognitive processes - how the human brain works-and their usage in and integration into knowledge engineering/expert systems technologies. ${ }^{16}$

\section{The Importance of Cognitive Skills}

Regretfully, the thinking or reasoning skills that enable developing cognitive models and related thinking skills have diminished considerably over the years among graduates of U.S. schools. If not corrected, this will negatively affect the American society and the competitive advantage of the U.S. economy. These shortcomings are documented in many studies. ${ }^{17}$ Drucker, for example, highlights that "... for the first time in human history it really matters whether or not people learn." ${ }^{\prime 8} \mathrm{He}$ emphasizes the need for members of society-individuals as well as organizations-to learn how to learn, and that the responsibility of teaching the cognitive skills needed to achieve this will be shared by schools and colleges and by employers. Denning also stresses the importance of an individual's ability to adapt and learn. ${ }^{19}$ This means having the cognitive skills to apply acquired knowledge to new business situations, being able to learn from each new job experience, and being able to practice entrepreneurial skills-in the complex and uncertain changing business environment, as well as in society as a whole. Knowing how to learn through cognitive modeling or mapping is an effective way not only to make that kind of adaptation easier but also to foster an individual's professional development.

In order to fill the many growing social needs of a changing society, educational institutions will have to change and business will have to pay more attention to employee professional development. One solution has been the development of corporate universities at individual companies..$^{20}$ The techniques described in this article are another step in helping fill this growing need for accelerated and more effective individual professional development.

\section{The Importance of Growing Professionally in Business}

The growing number in business jobs, such as chief learning officer, chief knowledge officer, manager of performance, or director of intellectual assets, substantiates the growing importance to manage a firm's "intellectual capital," that is "... the knowledge, experience and ideas of people at every level of the firm." ${ }^{21}$ These executives of self-styled learning organizations, such as Motorola, encourage learning, professional growth, and self-actualization of their employees, because constant learning is advantageous for both the employees and the firms, since it creates competitive advantage. Moreover, learning in business or on the job replaces loyalty as the main pillar of company cultures. ${ }^{22}$ Based on its research on employment strategies, the Institute of Management (IM) has consistently encouraged every worker/manager at every level to learn continuously throughout his or her lifetime. The IM emphasizes that the key to personal success is continuing professional development. ${ }^{23}$ Other studies and sources, such as Fisher, Nelton, Prestwood, Sherman, Ulrich, confirm these facts and trends. ${ }^{24}$

Professional growth depends on an individual's ability to systematically learn from experience. This article focuses on the learning involved in acquiring cognitive (thinking) skills to create generalized concepts/models of decision-making in areas related to an individual's profession. The construction of these cognitive models can be learned using cognitive modeling or mapping techniques drawn from expert systems (artificial intelligence) technologies, as shown in the following discussions. This approach has proven effective in a variety of learning situations. The following sections describe how cognitive mapping tools drawn from knowledge engineering (an artificial intelligence discipline in which they are used in developing expert systems) can be employed to help entrepreneurs both to make decisions and to grow professionally. The experiences described involve both the decision to become an entrepreneur and the decision involved in selecting a franchise offering.

\section{Experienced-based Learning}

Most of us have read a story. Most of us are also able to write summaries of experiences we have had-that is, write or tell our own stories. If we think about the experience and it involved a decision or action on our part, we can be 
prompted to include the reasons why we made the decision or took the action and why it did or did not work. We might also be able to sketch out the possible alternative decisions or solutions and the relationships among factors and our judgments about these factors that led to our decision or action. These are called "reasoning processes" or "heuristics"- that is, rules of thumb at work.

The parts that need to be included in the story to make this a useful exercise are:

- the possible decisions or actions;

- the general situation factors affecting the decision and ways required information was obtained;

- the specific situation factors considered in making the decision or taking the action;

- the reasoning process (and judgments) which led from the factors to the decisions/actions.

Once a story is in hand, we have a basis for teaching or learning key conceptual skills which an individual needs in order to learn from experience and grow professionally. The process involved is shown in Exhibit 1. The following discussions describe some learning experiences and techniques for using them to grow professionally. They present an orientation useful in any application learning program. For discussion purposes, however, the examples are limited to business management situations.

\section{An Example of the Learning Process}

As a start, describe a simple decision made recently. For example, the situation may involve a decision often facing business students and managers (e.g., whether to go into business for themselves or to work, or continue working, for someone else).

Initially, through reading, observation and/or experience, one workshop participant, Betty Mercer, began to describe some of the requirements of going into business for herself: the financial investment, long hours and risk taking, skills appropriate to the business, ability to handle people (workers/customers), stamina requirements, etc. After sketching out a profile of the perceived requirements, she began to explore her own capabilities to meet these requirements. These included temperament, interests, education and training, financial assets available, personal goals, any physical limitations, family obligations, and the like. The possible initial recommendation or decision, based on an analysis of these factors, would initially be "likely to succeed or not likely to succeed as an entrepreneur," depending how high or low she rated in each requirement factor area. Her initial outline of such a decision is given in Exhibit 2.

The participant is not expected to instantly arrive at a perfect outline or model. There may be a series of dia- grams, which are hopefully "successively more accurate approximations of reality." An individual rarely fully replicates reality, especially in the management decision-making/action area; the person only works for a pretty good working replication or model. The emerging refinement process through which the model is fine-tuned might involve such tasks as reading key books on the subject, 25 talking with local merchants and store owners, and reading cases and newspaper and magazine articles.

Clearly, more is involved in the decision than just a yes/no answer. It is important to identify one's own weak areas, such as work habits, in order to improve the chances of success by correcting bad habits, as is indicated under the recommendations box in Exhibit 2. Also it is important to know what kinds of business the individual is best suited for. In addition, it is important to determine how the comparisons are made between requirements and personal qualifications, and then expand the outline model as is done for the "interests" factor segment in Exhibit 2 and later in this article. These decisions require more complex decision processes, which can be modeled at later stages. For the moment, only a basic model is being developed.

The same process could be gone through when examining the decision involved in determining which major subject to take at school or what kind of job to seek. First, define the available options, the general job or profession requirements, and then the personal qualifications of the individual to meet those requirements. The pattern is then outlined as in Exhibit 2 or as in the other decision/action situations modeled in the exhibits that follow. Once the pattern or model is outlined, it is reused to evaluate each job opportunity or the available professional majors at school in relation to the individual's qualifications. At the same time, the person keeps refining the model or outline and in order to do a faster and more thorough and systematic job each time, and at the same time revise the model.

In this sense, the initial example is an exercise in the professional growth process outlined in Exhibit 1. This example shows how cognitive modeling tools used in knowledge engineering can be adapted to help an individual to formulate a clear picture of his or her entrepreneurial capabilities systematically and in a time-efficient way.

\section{An Extension of the First Example}

One workshop participant discussed his recent experience of considering going into business for himself through buying a fast-food franchise. After he gathered preliminary information about franchising in general and about one offering in particular, Robert London visited a consultant in the field for advice.

Rob, age 31 and single, has worked in investment banking for the last six years and prior to that worked in a branch of a suburban bank. He holds a bachelor's and a 


\section{Exhibit 2}

Rough Sketch of Individual Career Choice-Entrepreneur

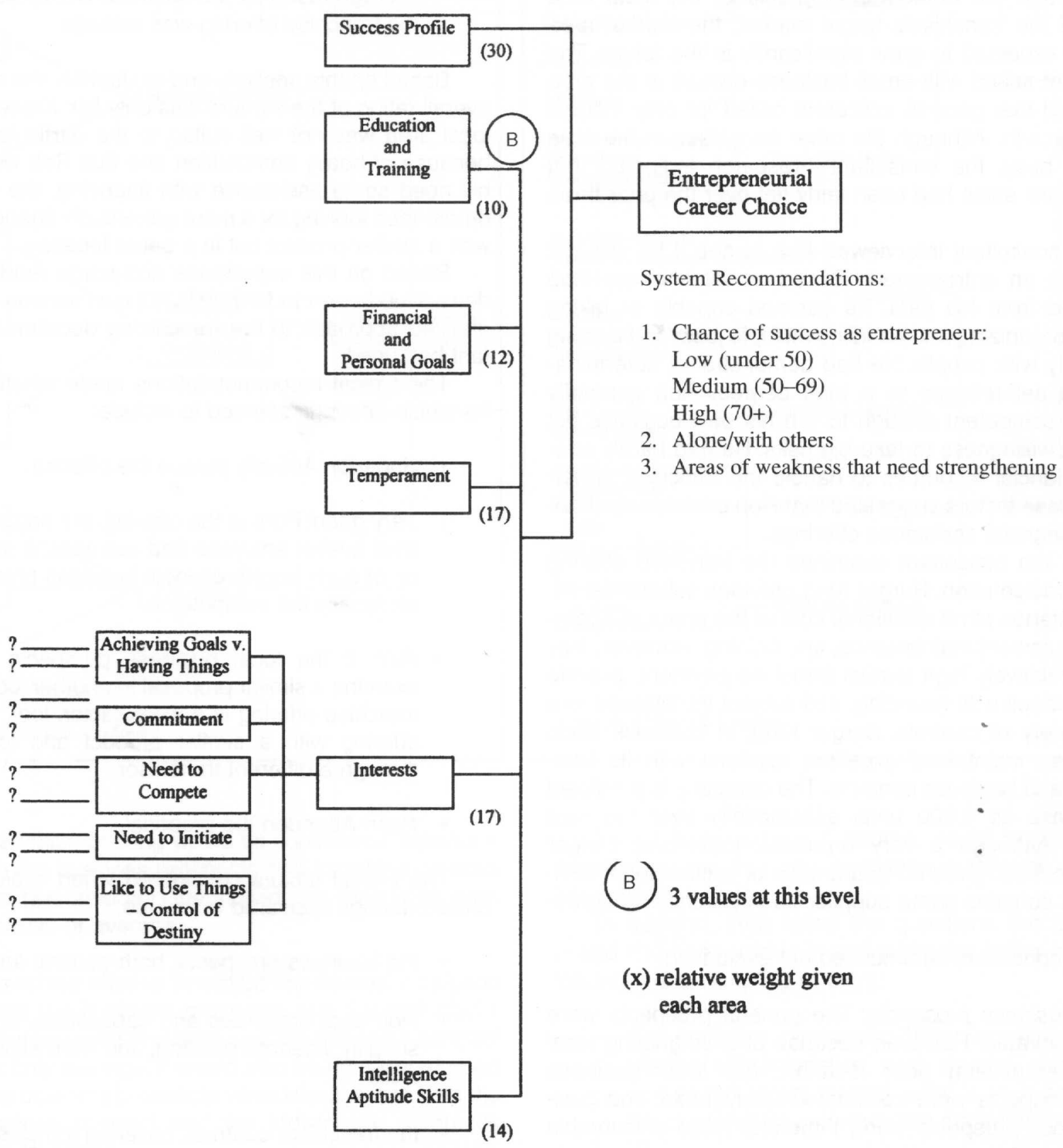

master's degree in business and lives in a rented apartment in a middle-class suburban area near a major city. He engaged a consultant in the field to help him in deciding whether or not to purchase a Burger King franchise near his home.

The consultant first collected background information. In terms of general business prospects, the product was examined for growth potential and staying power. Since fast-food products are common products consumed by many segments of the general population, ample demographic and market studies were available that showed that the overall growth prospects were modestly favorable.

However, an analysis of the local area revealed several weak points. The consultant found that the location Rob was looking at was already saturated with competition, including a McDonald's, a Wendy's and a Roy Rogers, all 
within a mile radius of each other. In addition, the franchise Rob was interested in would be located near an exit ramp to a major highway, but would be the last eating place that travelers would reach coming off the highway exit.

Although the demographic profile of the local area matched the franchise's target market, the market area was not expected to grow significantly in the future. The consultant talked with small business owners in the area and found that general indicators called for only modest overall growth. Although the other franchises in the area seemed busy, the consultant's research indicated that competitors' sales had been fairly flat over the prior three years.

The consultant interviewed Rob to see if he was cut out to be an entrepreneur. Based on experiences Rob described from his past, he seemed capable of taking charge, organizing and handling multiple jobs, and dealing effectively with people. He had demonstrated determination and self-reliance to a high degree. Rob generally seemed competent enough to run his own business but lacked a willingness to take big risks. He had barely adequate financial resources to handle the franchise investment. These factors suggested that Rob examine the franchise's financial assistance offerings.

Next the consultant examined the franchise offering under consideration. Burger King provides substantial initial assistance at no additional cost in the areas of operations, equipment maintenance, and training. However, they have a relatively high annual franchise payment, provide no assistance with financing, and subject franchisees to a wide variety of controls. Burger King, in business since 1954, has maintained excellent relations with its franchisees and business contacts. The company is predicted to increase its 4,000 units substantially over the next decade. Although a very reputable franchisor, Burger King's contract gives no guarantees of exclusivity of territory and contains some supplier tie-in purchasing agreements.

The consultant summarized her evaluation:

- Business prospects: The general prospects were favorable. However, because of a stagnating local market and poor location, the local business prospects were considered unfavorable. The business prospects were, therefore, rated unfavorable overall.

- Individual resources and capabilities: Because Rob had favorable personal, financial, and business skills and resources, the overall rating was favorable in this key factor area.

- Franchisor offering: Franchisor support was favorable. However, due to the lack of financial assis- tance and only fair fee schedule, the reasonableness of the deal was rated average. Although Burger King's reputation is excellent, lack of exclusivity of territory and tie-in agreements yielded an average rating for the contract. The overall rating for the franchise offering was average.

Based on this analysis and evaluation, the consultant's overall rating of the venture was only fair. Knowing that the local area was not well suited to the particular franchise because of heavy competition and that Rob would probably need some assistance with financing, the expert recommended looking for a more generously financed offering with a similar product but in a better location.

Based on this experience and some reading he had done, Rob began to formulate his own version of the generalized approach to the franchising decision the consultant had used.

The typical recommendations made when evaluating franchise offerings seemed to include:

- Superior: Actively pursue the offering.

- Very good: Pursue the offering, but commit to it only after further analyses and evaluations are completed of such factors as local business prospects, and especially the competition.

- Fair: If the local business prospects are weak, examine a similar proposal in another location; if the franchise offering is a weak factor, look for another offering with a similar product and location, but through a different franchisor.

- Poor: Abandon the proposal.

The critical factors considered when evaluating franchise offerings appeared to include:

- the business prospects, both general and local

- individual resources and capabilities, such as personality, financial position, and work experience and skills

- the franchisor contract, covering franchisor support, the reasonableness of the deal, and the franchisor character.

Based on this analysis, Rob prepared the outline shown in Exhibit 3A.

- In general, the way the consultant reasoned from these factors (his "if-then" heuristics or rules of thumb) in reaching a conclusion seemed to be: 


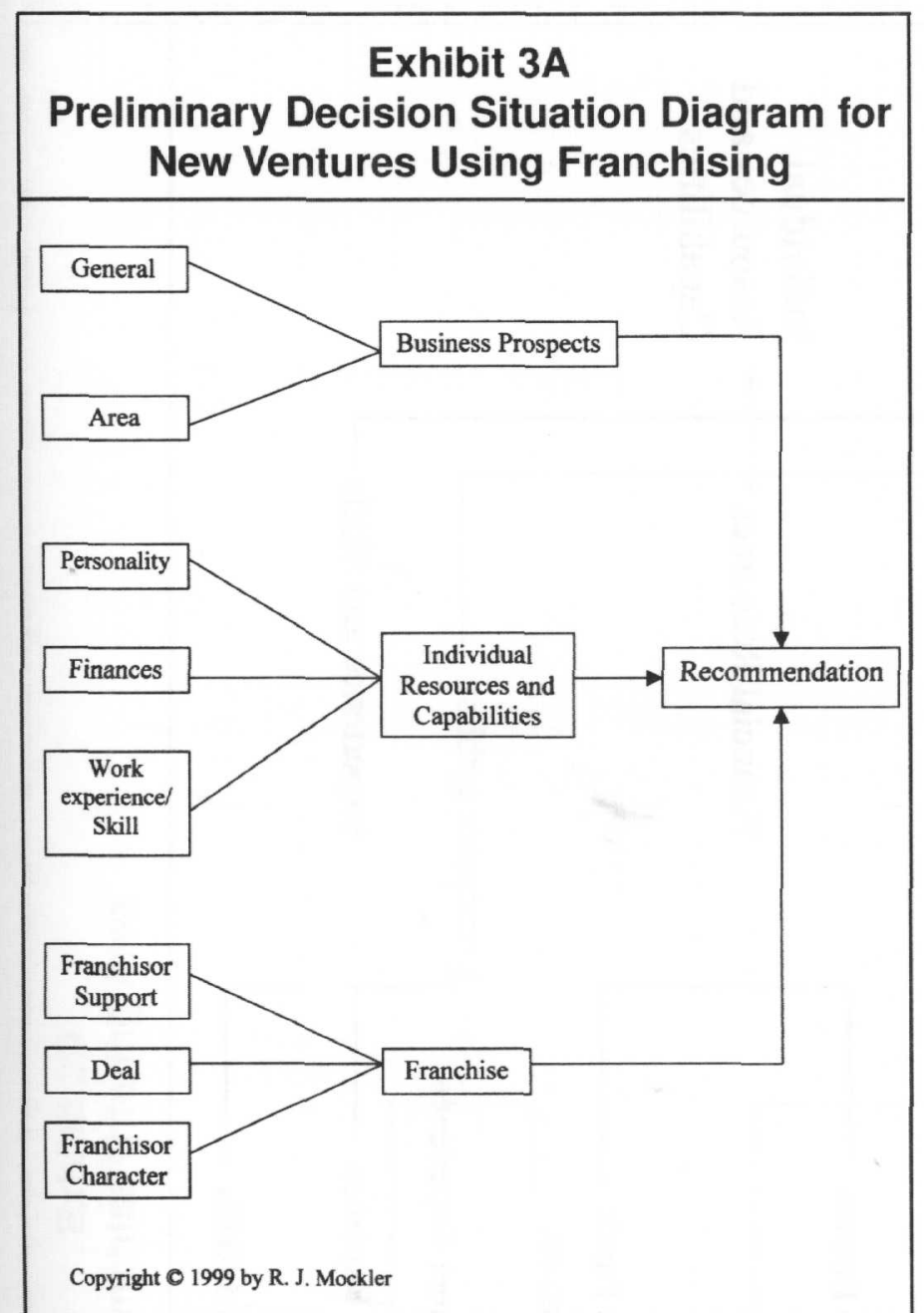

- A franchise offering would be considered superior if both the business prospects and franchise contract were favorable and the individual's resources were favorable or average.

- A franchise offering would be considered very good if both the business prospects and the individual's resources were favorable and the franchise contract was only average. It would also be considered good if the business prospects were average and both the franchise contract and the individual's resources were favorable.

- A franchise offering would be considered fair if both the business prospects and the individual's resources were average and the franchise contract was average or favorable.

- A franchise offering would be considered poor if any of the critical factors were considered unfavorable.

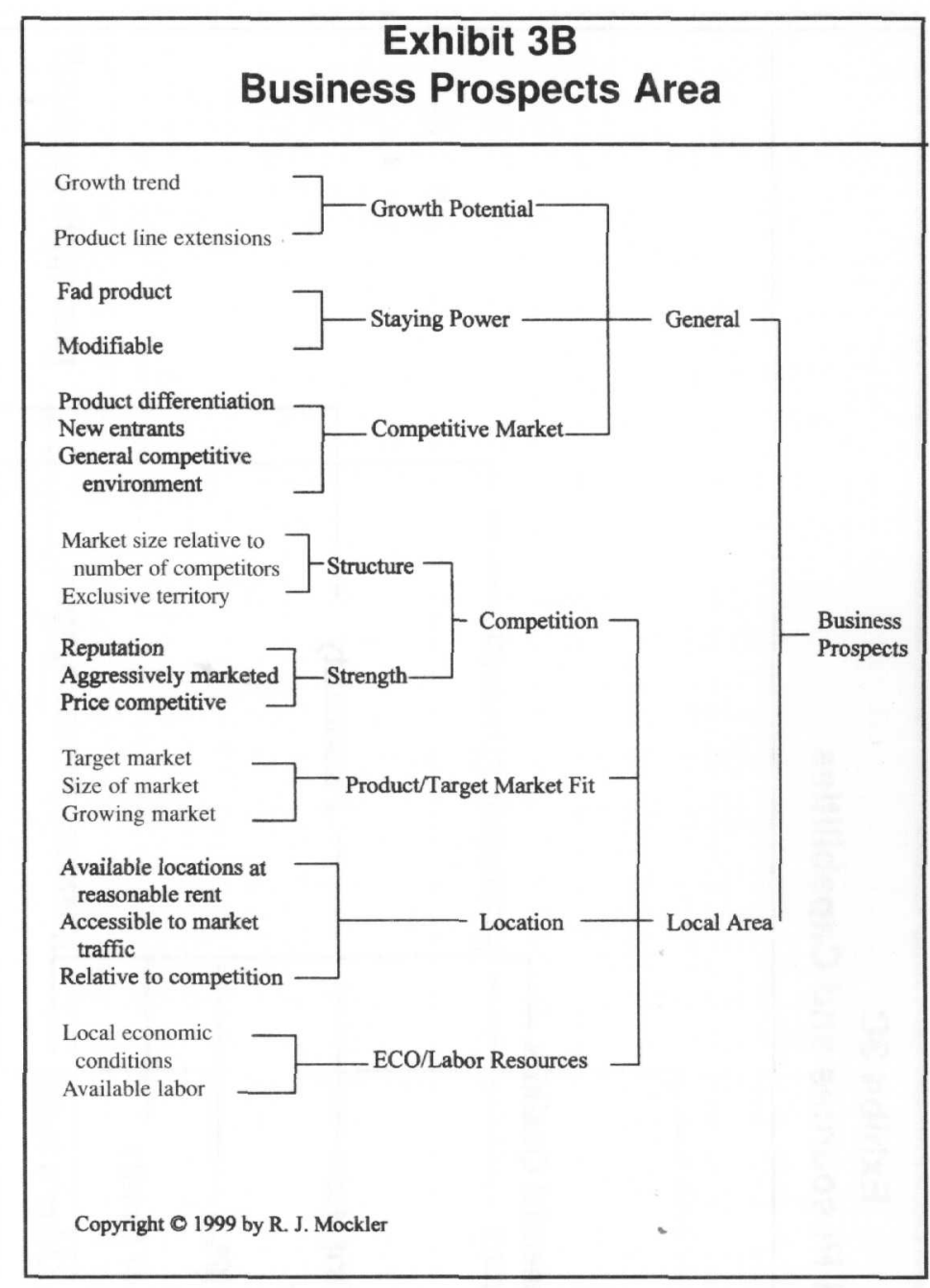

These conclusions, of course, could be modified in some instances through negotiation or through additional information.

In addition, Rob listed the questions the consultant asked and answered in investigating the factor areas. The following is a sampling of them:

- For business prospects: "After examining demographic characteristics, such as age, income, and size of the target market, what is your estimate of the potential for growth in the market in general?"

- For individual resources and capabilities: "What amount of money do you have and how much are you able to borrow?"

- For the franchise offering: "What is the failure rate of new franchisees in the past?" and "Has the general evaluation of the franchisor by former and current franchisees been favorable?" 


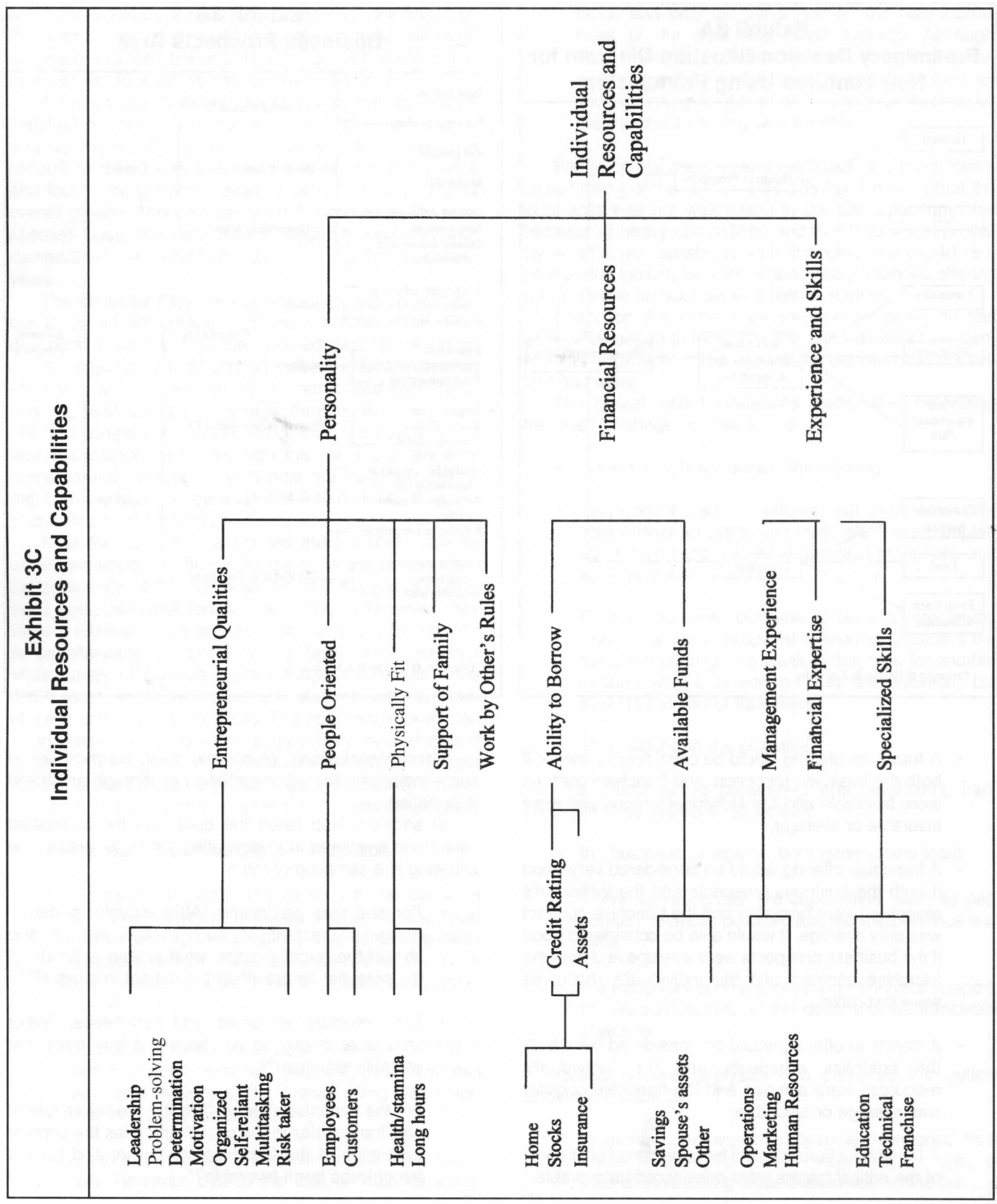

72 NEW ENGLAND JOURNAL OF ENTREPRENEUASHIP 


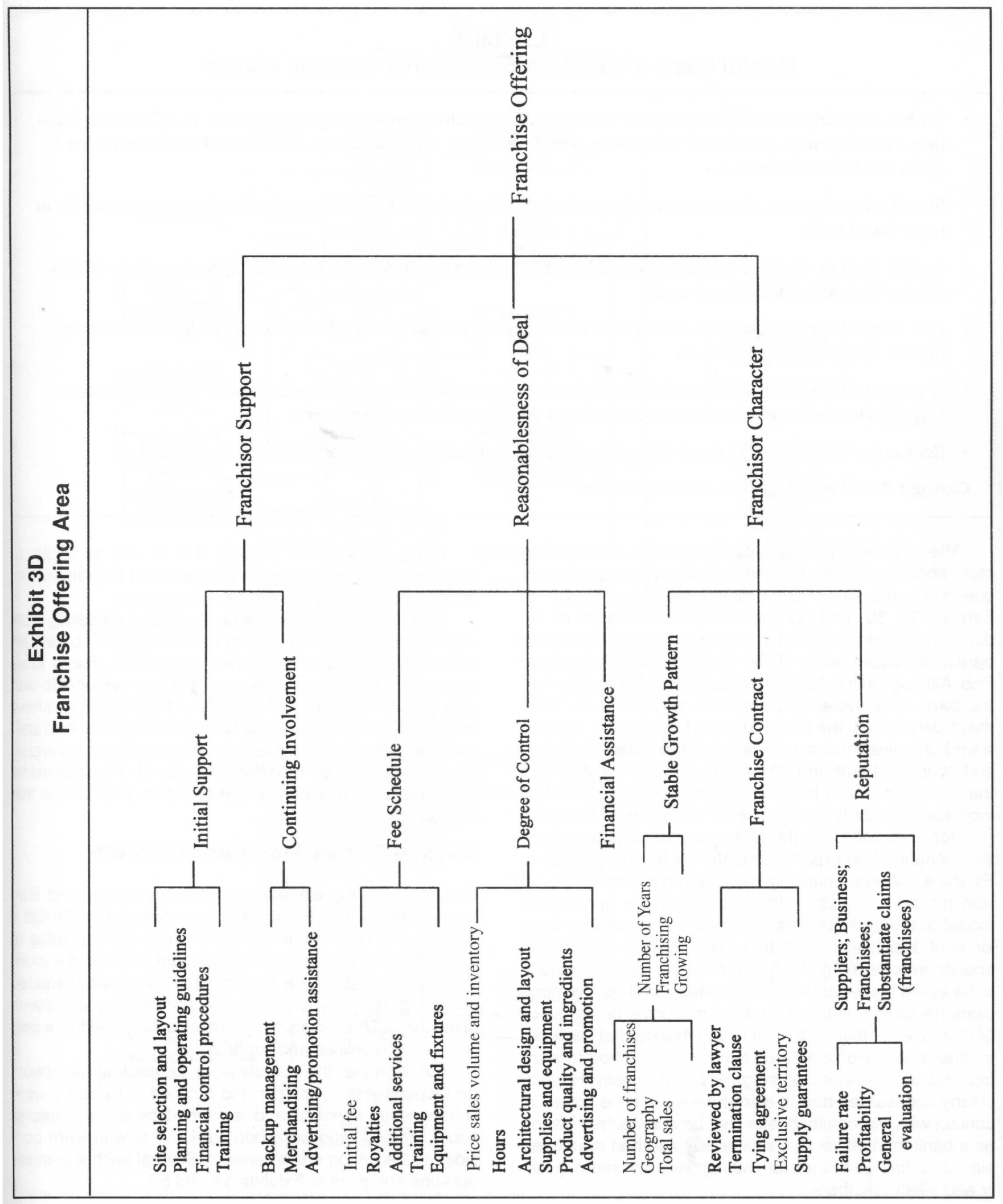

LEARNING HOW TO LEARN 73 


\section{Exhibit 4 Helpful Steps in Developing Structured Decision Models}

- Write a very detailed scenario (story) or how the task or decision under study is carried out in a particular situation, including such specifics as time, place, people involved, and other actual events which would occur on a given day in a real situation.

- Identify the recommendations that can be made in the kind of situation ;under study (limiting your answer to no more than 4 or 5 ).

- specify the 3 or 4 critical factors considered in making these recommendations and describe how these factors affect which recommendations made.

- List 10 or 12 specific questions which need answering in order to obtain information about the critical factors used to make a recommendation.

- If you are dealing with a diagnostic situation, reduce it to a technical manual outline and describe alternative ways this manual might be used to answer 3 or 4 specific questions or problems.

- Reexamine samples of existing KBS and transfer the structured information to an expert systems shell.

Copyright (C) 1999 by R. J. Mockler. All rights reserved.

After reviewing the consultant's summary and reading more about franchising in general, Rob expanded the list of questions and drew the detailed diagrams shown in Exhibits $3 B, 3 C$, and $3 D$. Exhibit $3 C$ is a variation of the decision outlined in Exhibit 2, a variation appropriate to the particular requirements of the franchise situation and to Rob. Although still in fairly rough form, Rob felt he now had the basis of a systematic approach as to how to make these decisions in the future. He was beginning to develop a kind of professional expertise for making these decisions and concluded that he had wisely used his investment in the consultant's visit to grow professionally since he had increased his ability to make better decisions on his own.

Rob had done this through systematically organizing the scenario of his experience along the lines suggested in Exhibit 4 . He systematically reconceived or reconceptualized his story, enabling himself to develop a generalized model of the approach that he could use in making these kinds of decisions in the future. His approach covered the specific information gathered from the situation (questions to be asked in relevant key factor areas), the possible decisions (recommendations), and the reasoning or heuristics (if-then rules of thumb) that went into making that decision. In other words, Rob appeared to have learned how to learn from his experiences and so grow professionally. $\mathrm{He}$ also clearly had learned how to learn from experts he comes in contact with. He admitted later that he approached his job as a bank loan officer in a similar way and had developed similar routine guidelines for making decisions more quickly and effectively there.
Rob's experiences showed that it was possible to acquire or enhance a systematic approach to professional development through guidance and practice.

This example also shows how cognitive modeling tools used in knowledge engineering can be adapted to help an entrepreneur in several different ways. First, these tools can help to capture general expertise in a systematic and time-efficient way that can help the individual entrepreneur to apply that expertise to new business situations. And second, these tools can help to formulate a professional repertoire of approaches of different kinds of entrepreneurial decisions, such as the franchise selection described in this section.

\section{Ways to Further Professional Growth}

As seen from the experiences of Betty Mercer and Rob London, growing professionally as suggested in Exhibit 1 requires not only systematically creating general rules of thumb (heuristics) for handling different kinds of decisionmaking/action situations. Professional growth also requires practicing using these guidelines, and refining and developing them. This process might involve the individual's own or others' guidelines and experiences.

For example, the guidelines or conceptual framework developed by Betty Mercer and outlined in Exhibit 2 were subsequently modified and expanded by other entrepreneurs, experts, and workshop participants who were considering becoming entrepreneurs. Several such expanded versions are given in Exhibits 5A and 5B. 


\section{Exhibit 5A Career Strategy Decision}

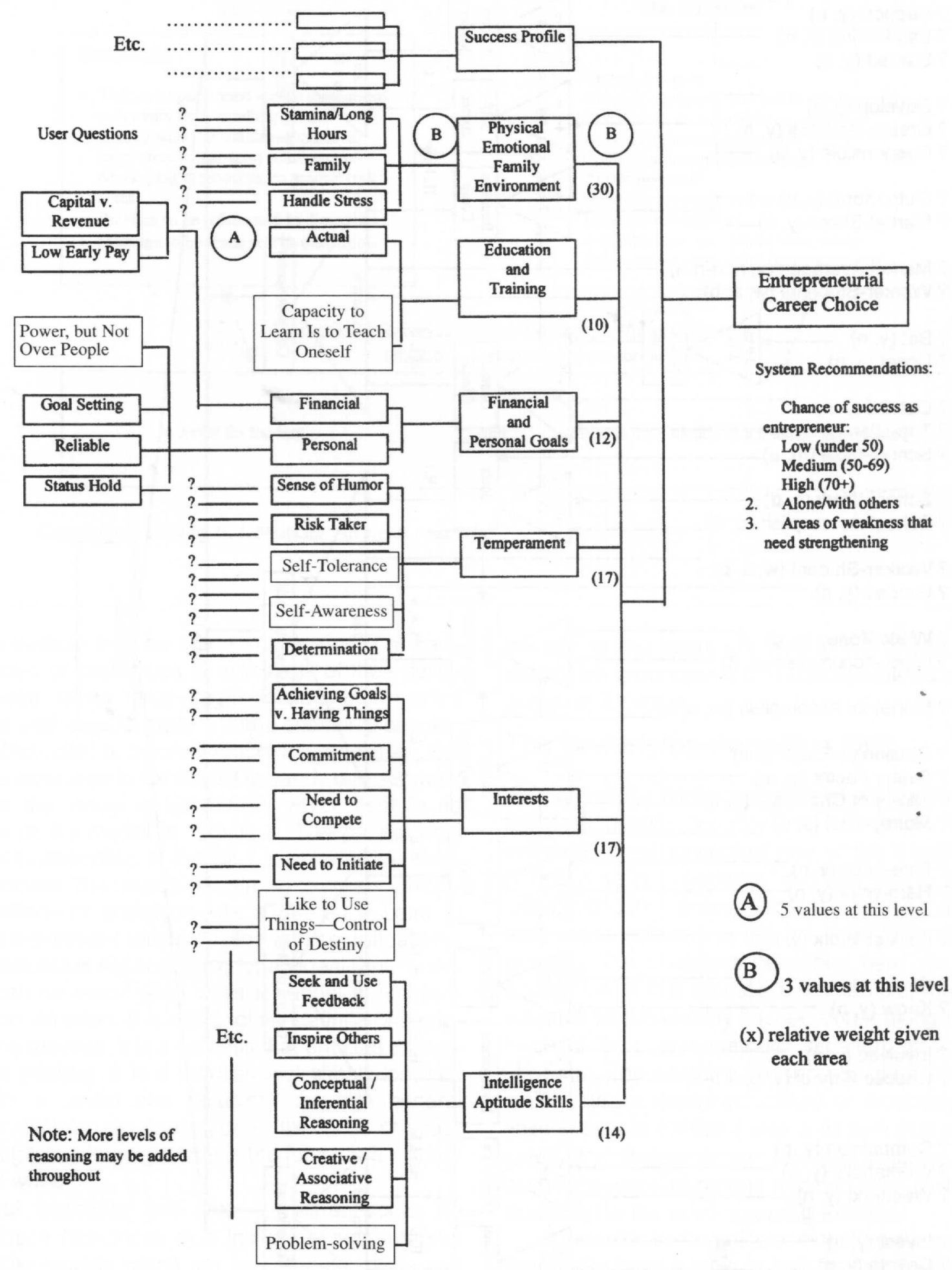




\section{Exhibit 5B \\ Career Strategy Decision: Interests Segment}

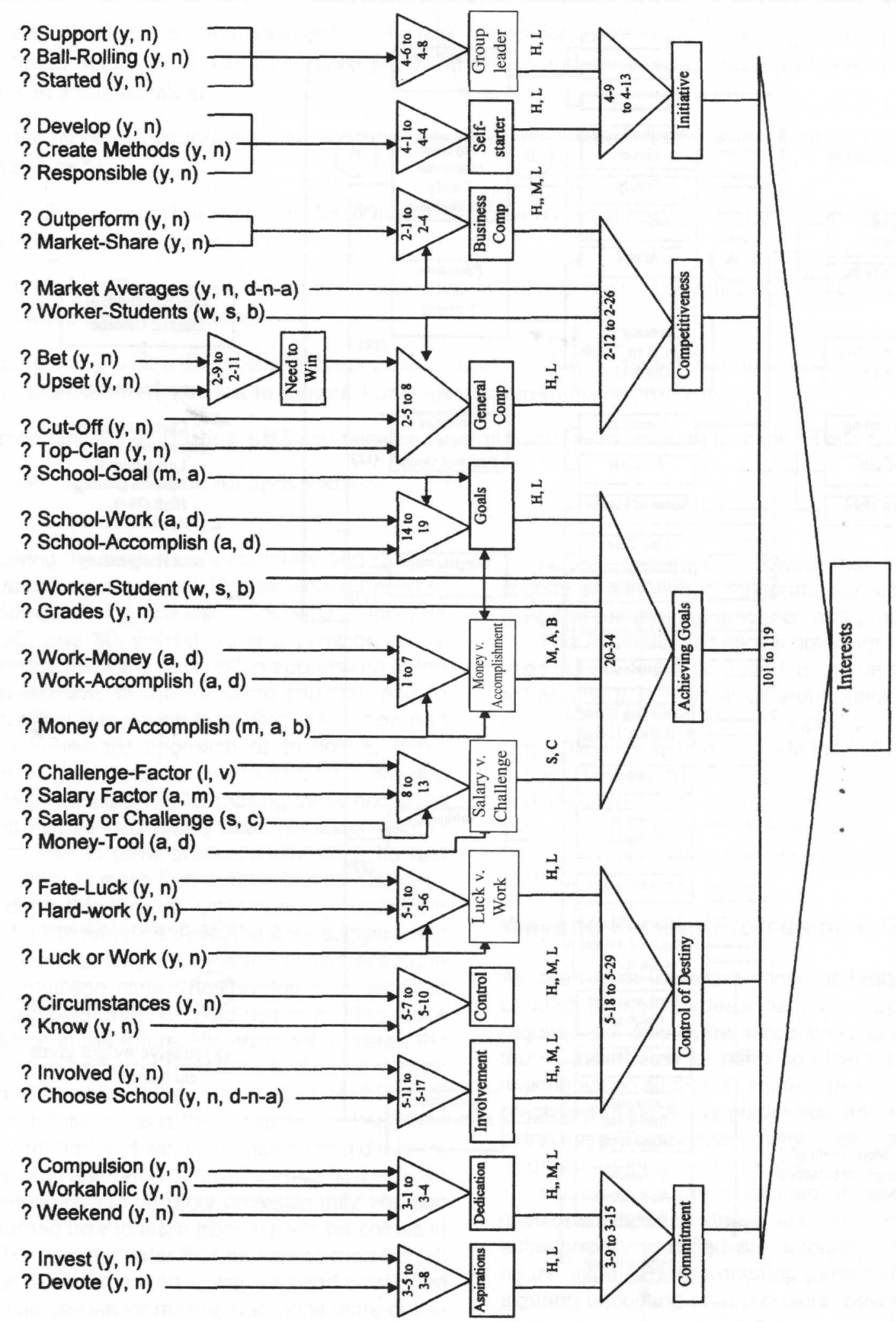

76 NeW ENGLAND JOURNAL OF ENTREPRENEURSHIP 


\section{Exhibit 6 \\ A Basic Emergent Entrepreneurial Contingency Process}

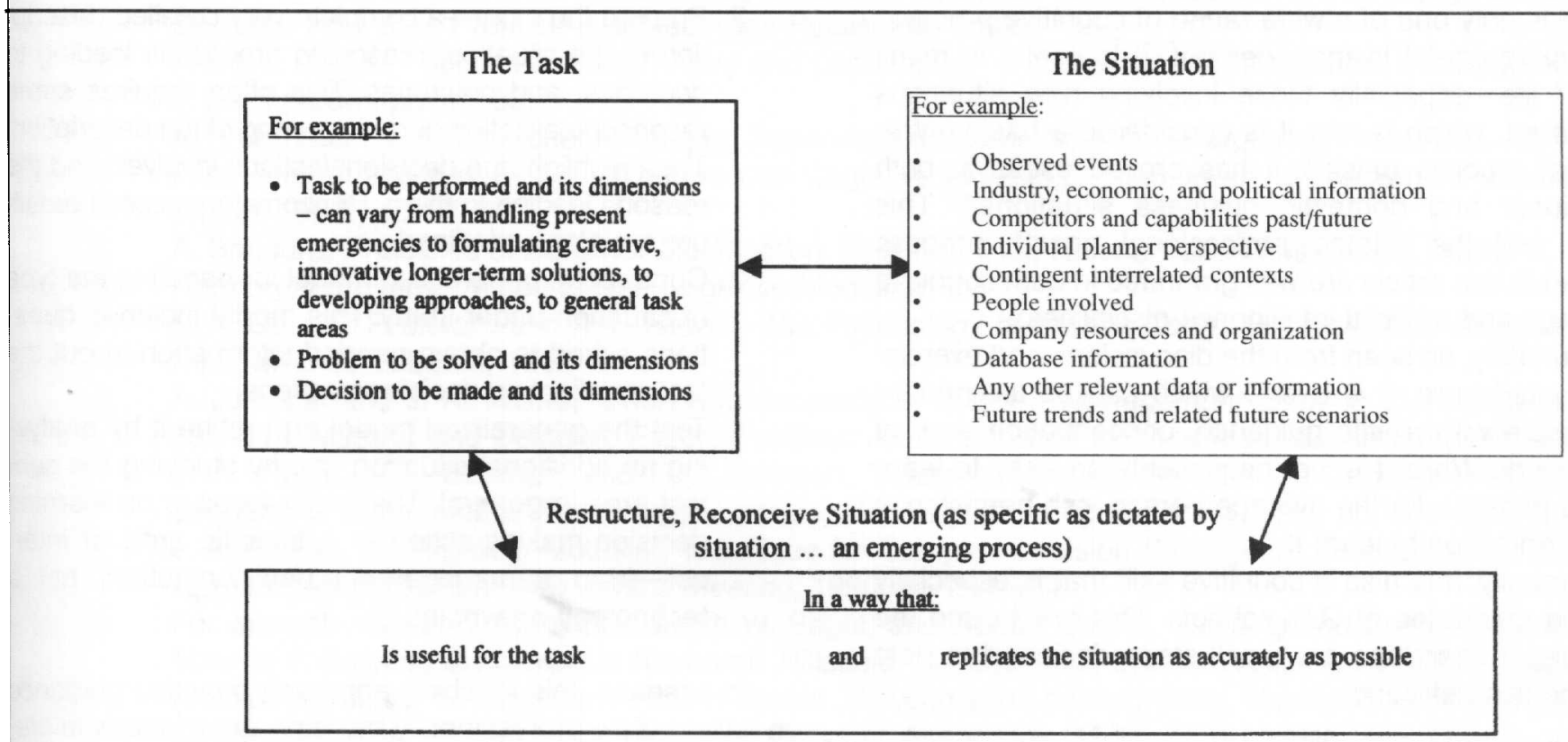

Copyright $(1999$ by R. J. Mockler. All rights reserved

The refinements may be made in any aspect of early working models or prototypes at any stage of their development. These refinements might involve more detail about factors and ways to explore them, additional options, or more sophisticated or different reasoning processes. For example, the extension in Exhibit $5 \mathrm{~B}$ expands one segment (interests) of the model in Exhibit 5A, which itself is an amplification of the model in Exhibit 2. The professional growth process described in Exhibit 1 is an adaptive, fluid, emerging process. The objective is simply to create a working visualization-or prototype-as a reference point to build on and experiment with in dealing with new situations.

The participant is not searching for an ideal "only" solution; there can be many good ways to model a decisionmaking/action situation. It is not a totally definite prescriptive or limiting process; it is a process that enables innovative, creative thinking. It is a process that simply involves searching for a useful and relatively accurate general guideline for decision-making/action in the kinds of situations a manager/leader might face in the future in his or her professional work.

Additional examples are given in other books by Mockler ${ }^{26}$ These references also include expert systems versions of the models which are on computer disks and which an individual can use and analyze. The basic approach in building all of these models and systems was the storytelling approach used in this article, during which stories are reconceived or reconceptualized along the lines shown in Exhibit 4.

\section{The Underlying Cognitive Skill}

The underlying thinking (cognitive) skill involved in the professional growth described in this article is a common entrepreneurial conceptual one, which is outlined in Exhibit 6 . This is an "it all depends" process, that is, a context-specific contingency process. It is a process that has whimsically been referred to as an individual's basic survival process. The situations described here are two kinds of application of this process. For example, the task in each situation was to identify the decision-making/action process involved in a management situation of the individual's choosing. The situation chosen was then studied in detail and in stages reconceptualized or reconceived along the lines shown in Exhibit 4 into a pattern that could be replicated in a decision/action situation diagram. Examples of such reconceptualizations were covered in this article and illustrated in the accompanying exhibits.

It is similar to the process of writing a paper or business report. You have a topic or task and a situation or research area. When you create an outline for the paper or report, you simply reconceive or reconceptualize the situation in a 
way appropriate for carrying out the task, as shown in the middle box in Exhibit 6 .

The process outlined in the three-box diagram in Exhibit 6 is only one of a wide range of cognitive processes and skills useful in management. It is useful in many areas of life-especially those involving new situations encountered, which is why it is considered a basic entrepreneurial process or skill. It has proved useful in both multinational and domestic business situations. ${ }^{27}$ This process and the related professional growth process described in this article are well grounded in both cognitive psychology and artificial intelligence disciplines.

Fortunately, as seen from the discussions and exercises presented here, it is a skill which can be learned by most people with a little guidance, concentration and, of course, work. While it is not necessarily an easy-to-learn skill, it is possible for the average person with persistence and determination to learn it.

Regretfully, it is also a cognitive skill that is especially lacking in graduates of U.S. schools. This article and the techniques it describes are small steps designed to help overcome this deficiency.

\section{Conclusions}

The approach described here has been used successfully during the past 10 years at St. John's University, New York, in the graduate (MBA) and upper-level undergraduate courses in the business school. The technique evolved from workshop exercises involving developing cognitive models for prototype knowledge-based systems. It was gradually refined for use in research projects in planning for business, especially in the entrepreneurial courses. The simplicity of this structured approach appealed to the students; its effectiveness was documented not only by student feedback, but also by comparing the quality of student output at the end of each of these courses to that of earlier ones. It was important to target the technique at very specific subject areas and narrow the scope to the abilities of the student, with undergraduates having very narrow, well-defined topics. Graduate students and executive seminar participants were found to be more capable of handling less-defined, broader business situations.

As shown earlier in this article, cognitive mapping tools/techniques have often been used effectively in helping students learn. The technique described here, as well as other similar tools in the past and present, such as Edward de Bono's CoRT, are largely drawn from the field of cognitive psychology. They have been successfully applied to the area of artificial intelligence and are now used in teaching and learning environments.

The professional growth project can be broken into four specific steps.

1. Select an appropriate topic and write a short description of the management situation chosen for the project, using guidelines such as those given in this article.

2. Prepare the story - a complete very detailed description of the situation, reasoning processes leading to decisions, and outcomes. This often requires some reconceptualization or restructuring of the description. Then highlight the decisions/actions involved and the reasons leading to them. Reasons for success or failure are also underlined.

3. Construct a generalized model for handling the type of situation under study. This model includes questions asked to obtain needed information about the factors affecting decisions/actions.

4. Test the generalized model and refine it by analyzing an additional situation and by studying the subject area in general. The major focus is on learning decision-making/action in a specific area of interest-from a management decision/action, not a technology, viewpoint.

In essence, this teaching approach provides guidance on how to grow professionally by using experiences to create professional heuristic guidelines. Such an exercise provides several benefits including:

- Increasing professional knowledge in the area of interest, such as accounting, finance, marketing, and operations.

- Acquiring knowledge in a management application context; that is, learning to put knowledge of a subject area to work in actual business situations.

- Going beyond case studies and learning how to learn from cases, as well as from individual experiences, and how to systematically increase professional competency by learning how to generalize the knowledge learned in a systematic way.

- Learning to use generalized knowledge to deal with new situations.

- Acquiring the capability to continue to grow professionally in a well-focused and time- efficient way.

Education comes from the Latin word meaning to "draw out." The learning and teaching approach described in this article is based on that concept, since it works with ("draws out") one's experiences and one's ability to generalize (or conceptualize) those experiences. It is what is known as active learning, a way research tells us is the best (and perhaps major) way to learn, since it helps one learn how to learn. 


\section{Endnotes}

1. Robert J. Mockler and Dorothy G. Dologite, Expert Systems: An Introduction to Knowledge-Based Systems. New York: Prentice-Hall/Macmillan Publishing, 1992.

2. Phillip J. Decker, "Social Learning Theory and Leadership," The Journal of Management Development 5 , no. 3 (1986), pp. 46-58.

3. A. P. Goldstein and M. Sorcher, Changing Supervisor Behavior. New York: Pergamon Press, Inc., 1974.

4. Paul Harmon and Kay Evans, "When to Use Cognitive Modeling," Training and Development Journal (March 1984), pp. 67-68.

5. A. Bandura, Principles of Behavior Modification. New York: Hot, Rinehart and Winston, Inc., 1969.

6. Harmon and Evans, "When to Use Cognitive Modeling"

7. S. K. Card, T. P. Moran, and A. L. Newell, The Psychology of Human-Computer Interaction. Hillsdale, NJ: Lawrence Erlbaum, 1983.

8. A. Johnson and J. W. Payne, "Effort and Accuracy in Choice," Management Science 31 (1985), pp. 395-414; Mockler and Dologite, Expert Systems: An Introduction to Knowledge-Based Systems; and J. W. Payne, J. R. Bettman, and E. J. Johnson, "Adaptive Strategy Selection in Decision Making," Learning of Experimental Psychology: Learning, Memory and Cognition 14 (1988), pp. 534-552; and J. A. Purcell, "A Cognitive Modeling Technique for Complex Decision Strategies," Proceedings of the Human Factors Society 34th Annual Meeting, 1990, pp. 254-258.

9. For example, Susan F. Chipman, Judith W. Segal, and Robert Glaser, Thinking and Learning Skills, Volume 1: Relating Instruction to Research. Hillsdale, NJ: Lawrence Erlbaum Associates, 1985; Susan F. Chipman, Judith W. Segal, and Robert Glaser Thinking and Learning Skills, Volume 2: Research and Open Questions. Hillsdale, NJ: Lawrence Erlbaum Associates, 1985; Kate McGilly, ed., Classroom Lessons: Integrating Cognitive Theory and Classroom Practice. Cambridge, MA: MIT Press, 1994; Robert F. Mulcahy, Robert H. Short, and Jac Andrews, eds., Enhancing Learning and Thinking. New York: Praeger, 1991; Gary D. Phye and Thomas Andre, eds., Cognitive Classroom Learning: Understanding, Thinking, and Problem Solving. Orlando, FL: Academic Press, Inc., 1986; and John T. Richardson, Michael W. Eyseneck, and David Warren Piper, eds., Student Learning; Research in Education and Cognitive Psychology. Milton Keynes, England: SRHE and Open University Press, 1987.

10. Dale H. Schunk and Antoinette R. Hanson, "Self-Modeling and Children's Cognitive Skill Learning," June 1989, pp. 155-163; and Decker, "Social Learning Theory and Leadership."

11. Sharon Begley, "Your Child's Brain," Newsweek, February 19, 1996, pp. 55-62.

12. Edward de Bono, Teaching Thinking. New York: Penguin Books, 1976.

13. Richardson, Eyseneck, and Piper, Student Learning; Research in Education and Cognitive Psychology.

Gerard I. Nierenberg, The Art of Creativity Thinking. New York: Simon \& Schuster, 1982.

David Boud, Rosemary Keogh, and David Walker, eds., Reflection: Turning Experience into Learning. New York: Nichols Publishing Co., 1985; Lyle E. Bourne, Roger L. Dominowski, Elizabeth F. Loftus, and Alice R. Healy, Cognitive Processes, 2nd edition, Englewood Cliffs, NJ: Prentice-Hall, 1986; Phye and Andre, Cognitive Classroom Learning: Understanding, Thinking, and Problem Solving; and Arnold Trehub, The Cognitive Brain. Cambridge, MA: MIT Press, 1991.

16. Stephen Andriole and Leonard Ademan, Cognitive Systems Engineering for User-Computer Interface Design, Prototyping and Evaluation. Hillsdale, NJ: Lawrence Erlbaum Associates, 1995; Dan Lloyd, Simple Minds. Cambridge, MA: The MIT Press, 1989; Robert J. Mockler, Contingency Approaches to Strategic Management: Integrating Basic and Applied Research. Research Monograph, New York: Strategic Management Research Group, 1992; Mockler and Dologite, Expert Systems: An Introduction to Knowledge-Based Systems; Jeffrey Rothfeder, Minds Over Matter: A New Look At Artificial Intelligence. New York: Simon \& Schuster, 1985; Roger N. Shepherd and Lynn A. Cooper, Mental Images and Their Transformations. Cambridge, MA: MIT Press, 1982; and Scott R. Turner, The Creative Process: A Computer Model of Story Telling and Creativity. Hillside, NJ: Erlbaum, 1994.

17. For example Peter J. Denning and Robert M. Metcalfe, Beyond Calculation: The Next Fifty Years of Computing. New York: Springer-Verlag, 1997; Peter Drucker, Managing for the Future. New York: Truman Talley Books/Dutton, 1992; Edward Fisher, "Reading Analysis is Called Lacking," The New York Times, April 29, 1955, pp. A1ff; Rudolph Flesch, Why Johnny Can't Read-and What You Can Do 
About It. New York: Harper \& Row, 1955; Rudolph Flesch, Why Johnny Still Can't Read. New York: Harper \& Row, 1981; Gene I. Maeroff, "Reading Data Indicate Decline in Reasoning Ability," The New York Times, April 29, 1955, pp. A1ff.

18. Drucker, Managing for the Future.

19. Denning and Metcalfe, Beyond Calculation: The Next Fifty Years of Computing.

20. John Authers, "Motorola Leads the Way in the Corporate University Sector," Financial Times, June 18, 1998 , p. 7.

21. Jay Stuller, "Chief of Corporate Smarts," Training (April 1998), pp. 28-37.

22. Doyle Young, "Constant Learning," Executive Excellence (April 1995), p. 19.

23. Roger Young, "It's Time to Learn to Help Yourself," Management Today (November 1995B), p. 5.

24. Anne Fisher, "Six Ways to Supercharge Your Career," Fortune, January 13, 1997, pp. 46-48; and Sharon Nelton, "How to Broaden Your Skills," Nation's Business, (December 1995), pp. 49; Donna C. L. Prestwood, "Seven New Principles of Leadership," The Futurist (January/February 1997), p. 68; Marilyn Sherman, "Launch Your Career Through Learning," Career World (March 1997), pp. 15-17; and Dave Ulrich, "Intellectual Capital = Competence x Commitment," Sloan Management Review (Winter 1998), pp. 15-26.

25. For example, James R. Cook, The Start Up Entrepreneur: How You Can Succeed in Building, Your Own Company Into a Major Enterprise Starting from Scratch. New York: Harper \& Row, 1987; Howard H. Stevenson, Michael J. Roberts, and H. Irving Grossbeck, New Business Ventures and the Entrepreneur, 2nd edition. Homewood, IL: Irwin, 1985; and Jeffrey A. Timmons, New Venture Creation, 2nd Edition. Homewood, IL: Irwin, 1985.

26. Robert J. Mockler, Knowledge-Based (Expert) Systems for Management Decisions. Englewood Cliffs, NJ: Prentice-Hall, 1989; Robert J. Mockler, Strategic Management: An Integrative Context-Specific Process. Harrisburg, PA: Idea Group Publishing, 1993; Robert J. Mockler, Multinational Cross-Cultural Management: An Integrative Context Specific Process. Westport, CT: Greenwood Press, 1997.

27. Mockler, Strategic Management: An Integrative Context-Specific Process; and Robert J. Mockler, Multinational Cross-Cultural Management: An Integrative Context Specific Process.
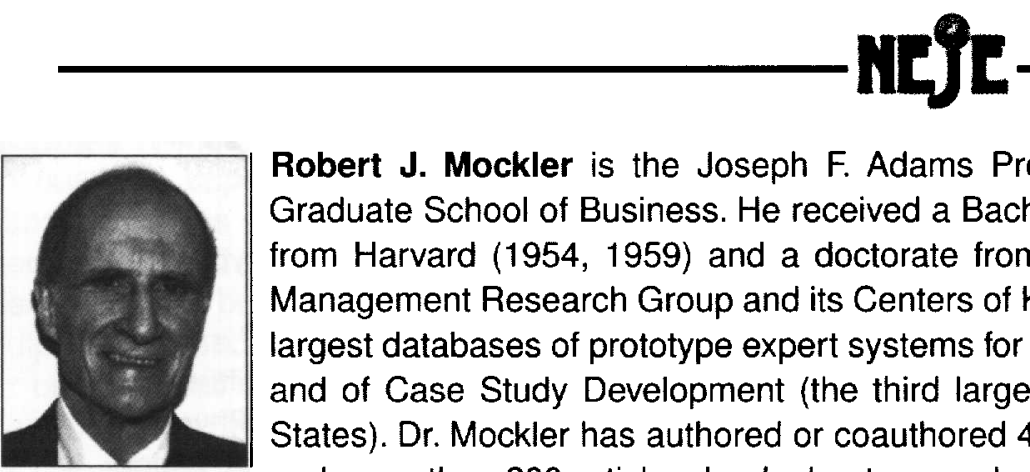

Robert J. Mockler is the Joseph F. Adams Professor of Management at St. John's University's Graduate School of Business. He received a Bachelor of Arts and Master of Business Administration from Harvard $(1954,1959)$ and a doctorate from Columbia (1961). He is dirèctor of the Strategic Management Research Group and its Centers of Knowledge-Based Systems for Business (one of the largest databases of prototype expert systems for management decision-making in the United States) and of Case Study Development (the third largest case study development program in the United States). Dr. Mockler has authored or coauthored 40 books and monographs, about 100 case studies, and more than 200 articles, book chapters, and presentations.

$\mathrm{He}$ has lectured and consulted worldwide, received national awards for innovative teaching (Decision Sciences Institute), been a Fulbright Scholar, and taught MBA courses in Rome, Milan, and Beijing.

Dr. Mockler has also successfully started, run, and eventually sold his own multimillion-dollar business ventures.

Dorothy G. Dologite is a professor of computer information systems at the Zicklin School of Business, Baruch College, City University of New York. She has written 12 books and many articles related to computer information systems. Her 15 years of computer industry experience before becoming an educator includes positions with computer hardware and software firms. She lectured and conducted workshops on computers in China, Russia, and many other countries. Dr. Dologite was a Fulbright Scholar in Malaysia on a strategic information systems project. Her research interests include applying knowledge-based system technology to management decision-making, diffusing technology in small businesses and in developing countries, and exploring creativity in information system products, processes, and people. 